\title{
As universidades estaduais brasileiras e as metas do PNE (2014-2024) para a educação superior: desafios de expansão e financiamento
}

\author{
The state universities and the PNE (2014-2024) goals for higher education: \\ challenges of expansion and funding \\ Las universidades estatales brasileñas y las metas del PNE (2014-2024) para la \\ educación superior: desafíos de expansión y financiación \\ RENATA RAMOS DA SILVA CARVALHO \\ NELSON CARDOSO AMARAL
}

\begin{abstract}
Resumo: Este estudo possui como objetivo apresentar qual seria a expansão necessária de matrículas e a ampliação no financiamento para que as universidades estaduais (UEs) do país contribuam com o êxito das metas do PNE (2014-2024) para a Educação Superior (ES). O estudo está estruturado em três sessões que se articulam para as análises e discussões: a) dos desafios de expansão para que o país alcance essas metas; b) dos desafios e das projeções de expansão para que as UEs colaborem com essa expansão; c) os desafios para a ampliação do financiamento das UEs para a promoção dessa expansão. Conclui-se que a expansão determinada para o alcance das metas do PNE (2014-2024) para a ES, e a consequente contribuição das UEs, mostra-se muito desafiadora e está ameaçada pelas políticas e ações que vêm sendo adotadas no país a partir do impeachment da presidente Dilma Rousseff.
\end{abstract}

Palavras-chave: PNE (2014-2024), metas para Educação Superior, universidades estaduais, expansão, financiamento.

\begin{abstract}
This study aims to present what would be the necessary expansion of enrollments and the increase of funding for the state universities (UEs) of the country to contribute to the success of the goals of Brazil's National Plan of Education - PNE (2014-2024) for higher education (ES). The study is structured in three sessions that are articulated for the analyzes and discussion: a) of the challenges of expansion for the country to reach these goals; b) of the challenges and the projections for the UEs to collaborate with this expansion; c) the challenges of expanding the UEs funding to promote this expansion. It is concluded that the expansion determined for the achievement of the PNE goals (2014-2024) for the UEs, and the consequent contributions of the UEs is very challenging and threatened by the policies and actions that have been adopted in the country since the impeachment of the President Dilma Rousseff.
\end{abstract}

Keywords: PNE (2014-2014); goals for higher education; state universities; expansion; funding. 
Resumen: Este estudio tiene como objetivo presentar cuál sería la expansión necesaria de matrículas y la ampliación en el financiamiento para que las universidades estatales (UEs) del país contribuyan con el éxito de las metas del PNE (2014-2024) para la educación superior (ES). El estudio está estructurado en tres sesiones que se articulan para los análisis y discusiones: a) de los desafíos de expansión para que el país alcance esas metas; b) los desafíos y las proyecciones de expansión para que las UEs colaboren con esta expansión; c) los desafíos para la ampliación de la financiación de las UEs para fomentar esta expansión. Se concluye que la expansión determinada para alcanzar los objetivos del PNE (2014-2024) para la UEs, y la consiguiente contribución de las UEs, se muestra muy desafiante y está amenazada por las políticas y acciones que se están adoptando en el país a partir del impeachment de la presidenta Dilma Rousseff.

Palabras clave: PNE (2014-2024); metas para la educación superior; universidades estatales; expansión; financiación.

\section{OS DESAFIOS DE EXPANSÃO DAS METAS DO PNE (2014-2024) PARA A EDUCAÇÃO SUPERIOR}

Com a aprovação do PNE (2014-2024), mediante a Lei n. 13.005, de 25 de junho de 2014, estabeleceram-se imperativos desafios a serem superados pelo Brasil, em dez anos, em todos os níveis educacionais. Sobre a ES, esta é pauta nas metas 12,13 e 14. A análise dessas metas, subsidiada por informações estatísticas do Instituto Nacional de Pesquisas Educacionais Anísio Teixeira (Inep), da Coordenação de Aperfeiçoamento de Pessoal de Nível Superior (Capes) e do Instituto Brasileiro de Geografia e Estatística (IBGE) evidenciam um cenário de desafios ao país, em especial quanto à expansão de matrículas, particularmente de matrículas públicas de graduação.

A meta 12 tem como objetivo elevar a taxa bruta de matrícula na ES para 50\% e a líquida para 33\% e determina que 40\% dessa nova expansão seja promovida por Instituições de Educação Superior (IES) públicas. No ano de 2014, para uma população entre 18 a 24 anos de 23.922 .743 habitantes, havia no país 7.828.013 matriculas na ES, o que correspondia a uma taxa bruta de $32,7 \%$ e líquida de $16,5 \%$.

Os dados da tabela 1 mostram os desafios e as projeções de expansão de matrículas e matrículas públicas na ES do país e por estado da federação, tendo em vista o proposto pela meta 12 de se atingir 50\% de taxa bruta no final de sua vigência e, ainda, considerando que $40 \%$ dessa nova expansão seja em matrículas públicas. Nessa perspectiva, os dados desta tabela também apresentam qual seria o acréscimo necessário dessas matrículas e seu percentual de crescimento para que o país e cada estado da federação obtivessem $50 \%$ de taxa bruta no ano de 
2024, com 40\% da nova expansão em matrículas públicas. Apresenta também qual seria o quantitativo total de matrículas e matrículas públicas no ano de 2024 para o êxito dessa meta.

Tabela 1 - Projeção da expansão de matrículas e matrículas públicas na ES de 2014 a 2024 para o alcance de 50\% de taxa bruta, no Brasil, regiões e estados da federação, no ano de 2024

\begin{tabular}{|c|c|c|c|c|c|c|c|c|c|}
\hline $\begin{array}{l}\text { Regiões } \\
\text { Estados }\end{array}$ & $\begin{array}{c}\text { Matrículas } \\
\text { na ES } \\
2014\end{array}$ & $\begin{array}{l}\text { Matrículas } \\
\text { públicas } \\
\text { na ES em } \\
2014\end{array}$ & $\begin{array}{l}\text { Taxa } \\
\text { bruta } \\
2014\end{array}$ & $\begin{array}{c}\text { Total de } \\
\text { matrículas } \\
\text { para o } \\
\text { êxito de } \\
50 \% \text { de } \\
\text { taxa bruta } \\
\text { em } 2024\end{array}$ & $\begin{array}{l}\text { Acréscimo } \\
\text { total de } \\
\text { novas } \\
\text { matrículas } \\
\text { (todas as } \\
\text { idades) }\end{array}$ & $\begin{array}{c}\% \text { de } \\
\text { crescimento } \\
\text { necessário } \\
\text { nas } \\
\text { matrículas } \\
\text { da ES de } \\
2014 \text { a } \\
2024\end{array}$ & $\begin{array}{l}\text { Acréscimo } \\
\text { de } \\
\text { matrículas } \\
\text { públicas } \\
\text { até } 2024\end{array}$ & $\begin{array}{c}\text { Total de } \\
\text { matrículas } \\
\text { públicas } \\
\text { para o êxito } \\
\text { de } 40 \% \\
\text { das novas } \\
\text { matrículas } \\
\text { em IES } \\
\text { públicas em } \\
2024\end{array}$ & $\begin{array}{c}\% \text { de } \\
\text { crescimento } \\
\text { necessário } \\
\text { nas } \\
\text { matrículas } \\
\text { públicas da } \\
\text { ES de } 2014 \\
\text { a } 2024\end{array}$ \\
\hline Brasil & 7.828 .013 & 1.961 .002 & 32,7 & 11.699 .810 & 3.871 .797 & $49 \%$ & 1.548 .719 & 3.509 .721 & $79,0 \%$ \\
\hline Norte & 609.120 & 202.633 & 26,2 & 1.240 .754 & 631.634 & $104 \%$ & 252.654 & 252.724 & $124,7 \%$ \\
\hline RO & 71.089 & 10.231 & 33,1 & 112.475 & 36.787 & $49 \%$ & 14.715 & 47.820 & $143,8 \%$ \\
\hline$A C$ & 35.489 & 11.160 & 34,8 & 61.729 & 24.568 & $66 \%$ & 9.827 & 57.294 & $88,1 \%$ \\
\hline AM & 157.530 & 52.963 & 29,1 & 294.701 & 137.171 & $87 \%$ & 54.868 & 126.719 & $103,6 \%$ \\
\hline $\mathrm{RR}$ & 27.221 & 12.033 & 38,8 & 39.982 & 12.761 & $47 \%$ & 5.104 & 33.277 & $42,4 \%$ \\
\hline PA & 204.876 & 70.911 & 18,9 & 566.277 & 361.401 & $176 \%$ & 144.560 & 1.273 .281 & $203,7 \%$ \\
\hline AP & 39.937 & 10.364 & 38,2 & 65.294 & 25.357 & $63 \%$ & 10.143 & 108.632 & $97,9 \%$ \\
\hline TO & 72.978 & 34.971 & 37,7 & 101.087 & 28.109 & $39 \%$ & 11.244 & 269.460 & $32,2 \%$ \\
\hline Nordeste & 1.646 .883 & 582.852 & 24,1 & 3.372 .955 & 1.726 .072 & $105 \%$ & 690.429 & 83.698 & $118,5 \%$ \\
\hline MA & 145.420 & 56.344 & 16,8 & 456.636 & 311.216 & $214 \%$ & 124.486 & 180.830 & $220,9 \%$ \\
\hline $\mathrm{PI}$ & 113.069 & 52.929 & 30,2 & 189.991 & 76.922 & $68 \%$ & 30.769 & 211.199 & $58,1 \%$ \\
\hline CE & 258.103 & 82.439 & 22,9 & 535.387 & 277.284 & $107 \%$ & 110.913 & 193.352 & $134,5 \%$ \\
\hline RN & 122.364 & 51.786 & 29,4 & 208.553 & 86.189 & $70 \%$ & 34.476 & 84.182 & $66,6 \%$ \\
\hline PB & 144.189 & 74.412 & 31,2 & 229.739 & 85.550 & $59 \%$ & 34.220 & 30.928 & $46,0 \%$ \\
\hline PE & 255.414 & 88.992 & 23,0 & 560.931 & 305.517 & $120 \%$ & 122.207 & 86.262 & $137,3 \%$ \\
\hline BA & 423.298 & 103.913 & 23,6 & 837.166 & 413.868 & $98 \%$ & 165.547 & 455.287 & $159,3 \%$ \\
\hline $\mathrm{AL}$ & 101.198 & 41.109 & 24,5 & 208.880 & 107.682 & $106 \%$ & 43.073 & 17.137 & $104,8 \%$ \\
\hline SE & 83.828 & 30.928 & 30,4 & 145.673 & 60.143 & $70 \%$ & 24.057 & 10.231 & $77,8 \%$ \\
\hline Sudeste & 3.557 .642 & 660.839 & 37,3 & 4.588 .304 & 1.030 .662 & $29 \%$ & 412.265 & 11.160 & $62,4 \%$ \\
\hline MG & 797.601 & 194.868 & 33,7 & 1.103 .681 & 306.080 & $38 \%$ & 122.432 & 46.215 & $62,8 \%$ \\
\hline ES & 150.588 & 29.720 & 33,9 & 225.856 & 71.463 & $46 \%$ & 28.585 & 20.507 & $96,2 \%$ \\
\hline RJ & 634.727 & 160.410 & 35,1 & 853.724 & 218.997 & $35 \%$ & 87.599 & 107.831 & $54,6 \%$ \\
\hline SP & 1.974 .726 & 275.841 & 40,3 & 2.405 .043 & 430.317 & $22 \%$ & 172.127 & 215.471 & $62,4 \%$ \\
\hline
\end{tabular}




\section{Tabela 1 - Projeção da expansão de matrículas e matrículas públicas na ES de 2014 a 2024 para o alcance de 50\% de taxa bruta, no Brasil, regiões e estados da federação, no ano de 2024}

\begin{tabular}{|c|c|c|c|c|c|c|c|c|c|}
\hline Regiões & $\begin{array}{c}\text { Matrículas } \\
\text { na ES } \\
2014\end{array}$ & $\begin{array}{c}\text { Matrículas } \\
\text { públicas } \\
\text { na ES em } \\
2014\end{array}$ & $\begin{array}{c}\text { Taxa } \\
\text { bruta } \\
2014\end{array}$ & $\begin{array}{c}\text { Total de } \\
\text { matrículas } \\
\text { para o } \\
\text { êxito de } \\
50 \% \text { de } \\
\text { taxa bruta } \\
\text { em 2024 }\end{array}$ & $\begin{array}{c}\text { Acréscimo } \\
\text { total de } \\
\text { novas } \\
\text { matrículas } \\
\text { (todas as } \\
\text { idades) }\end{array}$ & $\begin{array}{c}\text { \% de } \\
\text { crescimento } \\
\text { necessário } \\
\text { nas } \\
\text { matrículas } \\
\text { da ES de } \\
2014 \text { a } \\
2024\end{array}$ & $\begin{array}{c}\text { Total de } \\
\text { matrículas } \\
\text { públicas } \\
\text { para o êxito } \\
\text { de 40\% } \\
\text { matrículas } \\
\text { públicas } \\
\text { até 2024 } \\
\text { das novas } \\
\text { matrículas } \\
\text { em IES } \\
\text { públicas em } \\
2024\end{array}$ & $\begin{array}{c}\% \text { de } \\
\text { crescimento } \\
\text { necessário } \\
\text { nas } \\
\text { matrículas } \\
\text { públicas da } \\
\text { ES de 2014 } \\
\text { a 2024 }\end{array}$ \\
\hline Sul & 1.262 .929 & 346.439 & 38,0 & 1.535 .147 & 272.218 & $22 \%$ & 108.887 & 1.073 .104 & $31,4 \%$ \\
\hline PR & 467.444 & 130.379 & 36,2 & 601.375 & 133.931 & $29 \%$ & 53.572 & 248.009 & $41,1 \%$ \\
\hline SC & 315.627 & 117.395 & 38,7 & 383.355 & 67.728 & $21 \%$ & 27.091 & 317.300 & $23,1 \%$ \\
\hline RS & 479.858 & 98.665 & 39,3 & 550.418 & 70.560 & $15 \%$ & 28.224 & 447.968 & $28,6 \%$ \\
\hline Centro- & 751.439 & 168.239 & 39,8 & 962.651 & 211.212 & $28 \%$ & 84.485 & 29.720 & $50,2 \%$ \\
\hline Oeste & 118.291 & 31.798 & 37,3 & 158.346 & 40.055 & $34 \%$ & 16.022 & 455.326 & $50,4 \%$ \\
\hline MS & 162.194 & 41.859 & 40,7 & 200.782 & 38.588 & $24 \%$ & 15.435 & 183.951 & $36,9 \%$ \\
\hline MT & 252.397 & 61.305 & 31,5 & 415.932 & 163.535 & $65 \%$ & 65.414 & 144.486 & $106,7 \%$ \\
\hline GO & 218.557 & 33.277 & 59,1 & 187.967 & -33.245 & $-15 \%$ & 0 & 126.889 & $0,00 \%$ \\
\hline DF & &
\end{tabular}

Fonte: Inep - Censo da Educação Superior do ano de 2012. IBGE - Projeções da população brasileira por sexo e idade para o período de 2000 a 2060. Sistematização e cálculo realizado por este estudo.

Esses dados indicam que, até o ano de 2024, o país precisaria contar com a criação de 3.871 .797 novas matrículas de graduação na ES para conseguir obter $50 \%$ de taxa bruta. E esse acréscimo de novas matrículas corresponderia a $49 \%$ de crescimento, ou seja, 11.699.810 discentes matriculados. Para que 40\% dessas novas matrículas fossem em IES públicas, seria necessário que, do total, 1.548.719 fossem públicas, o que representaria $78 \%$ de crescimento e corresponderia a 3.509.721 matrículas públicas.

No estado da Bahia, seria necessária a criação de 413.868 novas matrículas na ES, sendo, dessas, 165.547 públicas. Essa expansão representa 98\% e 159,3\% de crescimento, respectivamente. No estado do Maranhão, Pernambuco, Ceará e Alagoas, esses percentuais de crescimento seriam, respectivamente, de $214 \%$ e $220,9 \%, 120 \%$ e $137,2 \%, 107 \%$ e $134,5 \%, 106 \%$ e 104,8\%. No Maranhão, que possuía a menor taxa bruta no ano de 2014, seria necessária a criação de 311.216 novas matrículas, sendo, destas, 124.486 públicas.

Embora o desafio da meta 12 seja determinado ao país e não aos estados da federação, é preciso problematizar essas desigualdades existentes quanto ao acesso à ES que são evidentes na apreciação dos dados apresentados. No ano 
de 2014, os estados da Bahia, Maranhão, Pernambuco, Ceará, Alagoas e Pará possuíam taxas brutas inferiores a $25 \%$. Por consequência, nesses estados, os desafios para a obtenção de 50\% de taxa bruta no ano de 2024 e $40 \%$ da nova expansão em IES públicas seriam mais graves e, aparentemente, insuperáveis.

Os dados do gráfico 1 retratam a evolução das matrículas públicas no país entre 2012 e 2016 e, também, apresentam a projeção do seu crescimento para o atendimento do determinado por essa meta, no que diz respeito ao crescimento de matrículas na ES. Por essa lógica de compreensão, seria necessário um crescimento de $66,8 \%$ entre 2016 e 2024, porque elas precisariam passar de 1.990.078 para 3.509.721, um audacioso crescimento, tendo em vista o cenário de pouca expansão desse setor entre 2012 e 2016.

Gráfico 1 - Evolução das matrículas públicas na ES no Brasil, de 2012 a 2016, e a projeção do seu crescimento para atender ao determinado pela meta 12 do PNE (2014-2024) de que 40\% da nova expansão sejam em IES públicas até 2024 .

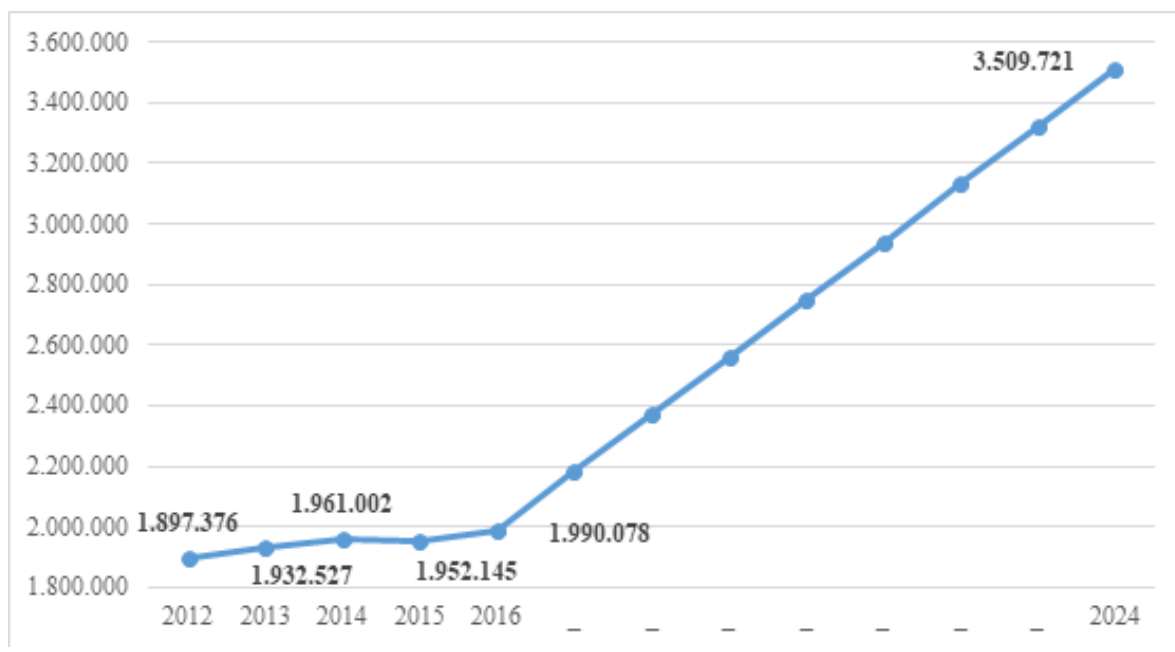

Fonte: Inep - Censo da Educação Superior - 2012 a 2016. IBGE - Projeção da população. Sistematização e cálculo realizado por este estudo.

A análise da dinâmica de crescimento e os desafios de expansão das matrículas públicas no contexto da meta 12 é essencial para se compreender a participação das UEs nesse contexto e se proporem discussões acerca desta participação, uma vez que elas compõem o conjunto das IES públicas. O desafio de crescimento das matrículas públicas no Brasil, para o atingimento do proposto por essa meta será utilizado como parâmetro para realizar as projeções da participação das UEs no êxito dessa meta. 
Quanto ao proposto pela meta 13 de "elevar a qualidade da Educação Superior e ampliar a proporção de mestres e doutores do corpo docente em efetivo exercício no conjunto do sistema de educação superior para $75 \%$, sendo, do total, no mínimo, 35\% doutores" (BRASIL, 2014, p. 23), os dados da tabela 2 mostram que, no ano de 2015, esses percentuais foram superados, pois $76,3 \%$ do total das funções docentes eram de mestres ou doutores, sendo 36,6\% de doutores. Esses dados revelam que o conteúdo principal dessa meta já estava muito próximo de ser alcançado.

Tabela 2 - Evolução das funções docentes em exercício totais e por titulação. Percentual de docentes mestres e doutores e percentual de doutores no Brasil - 2014 a 2016

\begin{tabular}{|c|c|c|c|c|c|c|c|}
\hline \multirow{2}{*}{ Ano } & \multirow{2}{*}{ Total } & \multicolumn{4}{|c|}{ Titulação } & \multirow{2}{*}{$\begin{array}{c}\% \\
\text { Mestres e } \\
\text { doutores }\end{array}$} & \multirow{2}{*}{$\begin{array}{c}\% \\
\text { Doutores }\end{array}$} \\
\hline & & SG/G & Especialista & Mestre & Doutor & & \\
\hline 2014 & 383.386 & 7.975 & 90.384 & 150.533 & 134.494 & 74,3 & 35,1 \\
\hline 2015 & 388.004 & 6.583 & 85.331 & 154.012 & 142.078 & 76,3 & 36,6 \\
\hline 2016 & 384.094 & 5.399 & 78.328 & 150.530 & 149.837 & 78,2 & 39,0 \\
\hline
\end{tabular}

Fonte: Inep - Censo da Educação Superior - 2001 a 2016. Sistematização e cálculo realizado por este estudo.

Além de estabelecer meta para a expansão de matrículas de graduação e a melhoria da titulação dos docentes que atuam na ES do país, o PNE ainda se ocupou em prever a elevação do número de mestres e doutores titulados na pós-graduação e determinou, na meta 14, "elevar gradualmente o número de matrículas na pós-graduação stricto sensu, de modo a atingir a titulação anual de 60.000 mestres e 25.000 doutores" (Ibidem). A tabela 3 apresenta os dados referentes à evolução do número de mestres e doutores titulados no Brasil, entre 2014 e 2016.

Tabela 3 - Evolução do quantitativo de mestres e doutores titulados no Brasil - 2014 a 2016

\begin{tabular}{|c|c|c|}
\hline \multirow{2}{*}{ Ano } & \multicolumn{2}{|c|}{ Brasil } \\
\cline { 2 - 3 } & Doutores & Mestres \\
\hline 2014 & 17.048 & 51.527 \\
\hline 2015 & 18.625 & 54.924 \\
\hline 2016 & 20.603 & 59.614 \\
\hline
\end{tabular}

Fonte: Geocapes - 2001 a 2016. Sistematização e cálculo realizado por este estudo. 
Tendo em vista o proposto pela meta 14 e os dados de 2016, podese afirmar que essa meta está próxima de ser cumprida: o desafio para o seu êxito no país consiste em titular anualmente mais 386 novos mestres e 4.397 novos doutores, até 2024 para o atendimento do proposto por essa meta. Quanto à titulação de doutores, é necessário um crescimento de $21,34 \%$ até o final da vigência do Plano.

Nessa conjuntura, é preciso problematizar a participação dos estados da federação no contexto de discussões e desafios inerentes às metas para a ES, em especial, quanto ao proposto para as IES públicas. Em suma, o alcance dessas metas inclui, necessariamente, a participação das UEs na ampliação de matrículas, na formação de seu quadro docente e na expansão de sua atuação na pós-graduação stricto sensu, uma vez que o referido Plano estabelece que "a União, os Estados, o Distrito Federal e os Municípios atuarão em regime de colaboração, visando ao alcance das metas e à implementação das estratégias objeto deste Plano" (BRASIL, 2014, art. VII).

As UEs criadas e mantidas pelos estados da federação são subordinadas aos sistemas estaduais de Educação de cada estado, com exceção para a oferta de educação a distância e a pós-graduação stricto sensu. Os estados possuem a competência legal para desenvolver seus processos regulatórios de autorização, reconhecimento, credenciamento e os de avaliação (BRASIL, 1996). A LDB/1996 também prevê que eles são os responsáveis por manter as Instituições Estaduais de Educação Superior (IEES) de seus sistemas de ensino.

Elas estão presentes em 22 estados da federação e possuem características, condições materiais e acadêmicas para a oferta de ES muito heterogêneas, segundo os estudos de Sampaio, Balbachesky e Peñaloza (1998), Martins (2000), Fialho (2005), Carvalho (2013). No ano de 2015, os dados do Inep indicavam a existência de 38 UEs no país, conforme relação nominal dessas instituições, por estado, constante no quadro 1. 


\section{Quadro 1 - Relação e distribuição das UEs brasileiras, por região e estado da federação}

\begin{tabular}{|c|c|}
\hline UF & UEs \\
\hline RR & Univ. Est. de Roraima - UERR \\
\hline TO & Fundação Univ. do Tocantins - Unitins \\
\hline AP & Univ. do Estado do Amapá - Ueap \\
\hline AM & Univ. do Estado do Amazonas - UEA \\
\hline PA & Univ. do Estado do Pará - Uepa \\
\hline PB & Univ. Est. da Paraíba - UEPB \\
\hline BA & $\begin{array}{c}\text { Univ. Est. de Feira de Santana - UEFS } \\
\text { Univ. Est. do Sudeste da Bahia - Uesb } \\
\text { Univ. Est. de Santa Cruz - Uesc } \\
\text { Univ. do Estado da Bahia - Uneb }\end{array}$ \\
\hline PI & Univ. Estadual do Piauí - Uespi \\
\hline MA & Univ. Est. do Maranhão - Uema \\
\hline PE & Univ. de Pernambuco - UPE \\
\hline CE & $\begin{array}{l}\text { Univ. Est. do Ceará - Uece } \\
\text { Univ. Est. do Cariri - Urca } \\
\text { Univ. Est. Vale do Acaraú - UVA }\end{array}$ \\
\hline AL & $\begin{array}{l}\text { Univ. Est. de Alagoas - Uneal } \\
\text { Univ. de Ciências da Saúde de Alagoas - Uncisal }\end{array}$ \\
\hline RN & Univ. do Estado do Rio Grande do Norte - Uern \\
\hline RJ & $\begin{array}{l}\text { Univ. do Estado do Rio de Janeiro - Uerj } \\
\text { Univ. Est. do Norte Fluminense Darcy Ribeiro - Uenf }\end{array}$ \\
\hline MG & $\begin{array}{l}\text { Univ. do Estado de Minas Gerais - UEMG } \\
\text { Univ. Est. de Montes Claros - Unimontes }\end{array}$ \\
\hline SP & $\begin{array}{c}\text { Univ. de São Paulo - USP } \\
\text { Univ. Est. Paulista Júlio de Mesquita Filho - Unesp } \\
\text { Univ. Est. de Campinas - Unicamp }\end{array}$ \\
\hline PR & $\begin{array}{c}\text { Univ. Est. de Londrina - UEL } \\
\text { Univ. Est. de Maringá - UEM } \\
\text { Univ. Est. do Norte do Paraná - Uenp } \\
\text { Univ. Est. de Ponta Grossa - UEPG } \\
\text { Univ. Est. do Centro Oeste do Paraná - Unicentro } \\
\text { Univ. Est. do Oeste do Paraná - Unioeste } \\
\text { Univ. Est. do Paraná - Unespar }\end{array}$ \\
\hline SC & Univ. do Estado de Santa Catarina - Udesc \\
\hline RS & Univ. Est. do Rio Grande do Sul - Uergs \\
\hline MS & Univ. Est. de Mato Grosso do Sul - Uems \\
\hline MT & Univ. Est. de Mato Grosso - Unemat \\
\hline GO & Univ. Est. de Goiás - UEG \\
\hline
\end{tabular}

Fonte: Sítios eletrônicos e documentos institucionais das UEs. 


\section{OS DESAFIOS DAS UES PERANTE AS METAS DO PNE (2014- 2024) PARA A EDUCAÇÃO SUPERIOR}

Tendo em vista a considerável participação das UEs na oferta de ES pública no país, torna-se relevante problematizar sobre como ocorrerá a participação dessas instituições no alcance das metas para a ES, em especial no segmento público, uma vez que as UEs, juntamente com as IES federais, são as principais promotoras dessa oferta pública no país. Nessa direção, os dados das tabelas 4 e 5 apresentam as projeções de expansão de matrículas públicas nas UEs, entre 2014 e 2024, para que elas possam contribuir com o êxito da meta 12, conforme proposta deste estudo, no Brasil e por estados, respectivamente. A metodologia utilizada nesta pesquisa para realizar essa projeção leva em consideração o percentual de matrículas públicas na ES que as UEs ofertaram em 2014, no Brasil (27,8\%) e em cada estado onde estão inseridas.

Para a análise desse desafio das UEs no país, foi calculado qual seria a quantidade de novas matrículas, considerando o alcance de $50 \%$ de taxa bruta no Brasil em 2024, por meio de cálculos da projeção populacional do IBGE. Desse total, calculou-se que, para o cumprimento da meta, 40\% dar-se-iam em IES públicas. Dessas novas matrículas públicas que seriam necessárias no país até 2024 , considera-se que 27,8\% seriam em UEs. Essa mesma metodologia foi seguida para apurar os desafios de expansão dos estados da federação que possuem UEs.

Por exemplo, no ano de 2014, as UEs do estado da Bahia foram responsáveis por $53,5 \%$ do total das matrículas públicas ofertadas nessa unidade da federação. Assim, a projeção da contribuição dessas instituições seria possuir a mesma participação percentual nas matrículas públicas no ano de 2024, tendo em vista o alcance de $50 \%$ de taxa bruta determinado pela meta 12 no estado, ou seja, do total dessas matrículas públicas necessárias no ano de 2024 para o êxito da meta, no estado da Bahia, calcula-se que 53,5\% sejam em UEs. 
Tabela 4 - Projeção da expansão de matrículas em UEs, entre 2014 e 2024, para elas contribuírem com o êxito da meta 12 do PNE (2014-2024) no Brasil, conforme metodologia deste estudo

\begin{tabular}{|c|c|c|c|c|c|c|c|c|}
\hline Regiões & $\begin{array}{l}\text { Taxa } \\
\text { bruta } \\
2014\end{array}$ & $\begin{array}{l}\text { Acréscimo } \\
\text { total de } \\
\text { matrículas } \\
\text { entre } 2014 \\
\text { e } 2024\end{array}$ & $\begin{array}{l}\text { Acréscimo } \\
\text { total de } \\
\text { matrículas } \\
\text { públicas } \\
\text { entre } 2014 \\
\text { e } 2024\end{array}$ & $\begin{array}{c}\text { Total de } \\
\text { matrículas } \\
\text { em UEs } \\
2014\end{array}$ & $\begin{array}{c}\% \text { de } \\
\text { matrículas } \\
\text { das UEs } \\
\text { nas } \\
\text { matrículas } \\
\text { públicas } \\
\text { em } 2014\end{array}$ & $\begin{array}{c}\text { Acréscimo } \\
\text { de novas } \\
\text { matrículas } \\
\text { necessário } \\
\text { nas UEs } \\
\text { de 2014 a } \\
2024\end{array}$ & $\begin{array}{c}\text { Total de } \\
\text { matrículas } \\
\text { necessário } \\
\text { nas UEs } \\
\text { em } 2024 \\
\text { para } \\
\text { contribuir } \\
\text { com a } \\
\text { meta } 12\end{array}$ & $\begin{array}{c}\% \text { de } \\
\text { crescimento } \\
\text { necessário } \\
\text { nas } \\
\text { matrículas } \\
\text { das UEs de } \\
2014 \text { a } 2024\end{array}$ \\
\hline Brasil & 32,7 & 3.871 .797 & 1.548 .719 & 546.086 & 27,8 & 430.544 & 976.630 & $78,8 \%$ \\
\hline
\end{tabular}

Fonte: Inep - Censo da Educação Superior - 2014 e 2016. IBGE - Projeção da população. Sistematização e cálculo realizado por este estudo.

Considerando a mesma participação proporcional de matrículas públicas de 2014, as UEs precisariam de mais 546.086 novas matrículas até o final de 2024, o que corresponde a um crescimento de $78,8 \%$, para contribuírem para o alcance dessa meta e permanecerem ofertando $27,8 \%$ do total das matrículas públicas no país no final da vigência do Plano, conforme indicado na tabela 4.

Uma das possibilidades de análise permitida pelos dados da tabela 5 está relacionada aos diferentes níveis de desafios impostos às UEs, por estados da federação, para que elas contribuam com o cumprimento da meta 12 , tendo em vista a metodologia deste estudo. Está sendo considerado o total de matrículas das UEs por estado, ou seja, no caso da unidade da federação que possui mais de uma UE; as informações são de todas elas juntas, ou seja, as 41.101 matrículas das UEs no estado do Ceará, no ano de 2014, previstas na tabela 5, correspondem às matrículas da Uece, Urca e UVA. 
Tabela 5 - Projeção da expansão de matrículas nas UEs, entre 2014 e 2024, para contribuir com o êxito da meta 12 do PNE (2014-2024), conforme metodologia deste estudo, nos estados que possuem UEs

\begin{tabular}{|c|c|c|c|c|c|c|c|c|}
\hline $\begin{array}{l}\text { Estados } \\
\text { que } \\
\text { possuem } \\
\text { UEs }\end{array}$ & $\begin{array}{l}\text { Taxa } \\
\text { bruta } \\
2014\end{array}$ & $\begin{array}{l}\text { Acréscimo } \\
\text { total de } \\
\text { matrículas } \\
\text { entre } 2014 \\
\text { e } 2024\end{array}$ & $\begin{array}{l}\text { Acréscimo } \\
\text { total de } \\
\text { matrículas } \\
\text { públicas } \\
\text { entre } 2014 \\
\text { e } 2024\end{array}$ & $\begin{array}{l}\text { Total de } \\
\text { matrículas } \\
\text { em UEs } \\
2014\end{array}$ & $\begin{array}{c}\% \text { de } \\
\text { matrículas } \\
\text { das UEs } \\
\text { nas } \\
\text { matrículas } \\
\text { públicas } \\
\text { em } 2014\end{array}$ & $\begin{array}{c}\text { Acréscimo } \\
\text { de novas } \\
\text { matrículas } \\
\text { necessário } \\
\text { nas UEs } \\
\text { de } 2014 \text { a } \\
2024\end{array}$ & $\begin{array}{c}\text { Total de } \\
\text { matrículas } \\
\text { necessário } \\
\text { nas UEs } \\
\text { em } 2024 \\
\text { para } \\
\text { contribuir } \\
\text { com a meta } \\
12\end{array}$ & $\begin{array}{c}\% \text { de } \\
\text { crescimento } \\
\text { necessário } \\
\text { nas } \\
\text { matrículas } \\
\text { das UEs de } \\
2014 \text { a } 2024\end{array}$ \\
\hline AM & 29,1 & 137.171 & 54.868 & 20.528 & 38,8 & 21.289 & 41.817 & $103,7 \%$ \\
\hline$R R$ & 38,8 & 12.761 & 5.104 & 4.186 & 34,8 & 1.776 & 5.962 & $42,4 \%$ \\
\hline PA & 18,9 & 361.401 & 144.560 & 14.407 & 20,3 & 29.346 & 43.753 & $203,7 \%$ \\
\hline AP & 38,2 & 25.357 & 10.143 & 2.594 & 25,0 & 2.536 & 5.130 & $97,8 \%$ \\
\hline TO & 37,7 & 28.109 & 11.244 & 9.155 & 26,2 & 2.946 & 12.101 & $32,2 \%$ \\
\hline MA & 16,8 & 311.216 & 124.486 & 23.261 & 41,3 & 51.413 & 74.674 & $221,0 \%$ \\
\hline $\mathrm{PI}$ & 30,2 & 76.922 & 30.769 & 17.313 & 32,7 & 10.061 & 27.374 & $58,1 \%$ \\
\hline $\mathrm{CE}$ & 22,9 & 277.284 & 110.913 & 41.101 & 49,9 & 55.346 & 96.447 & $134,7 \%$ \\
\hline $\mathrm{RN}$ & 29,4 & 86.189 & 34.476 & 11.016 & 21,3 & 7.619 & 18.635 & $69,2 \%$ \\
\hline PB & 31,2 & 85.550 & 34.220 & 20.404 & 27,4 & 9.376 & 29.780 & $46,0 \%$ \\
\hline PE & 23,0 & 305.517 & 122.207 & 17.115 & 19,2 & 23.464 & 40.579 & $137,1 \%$ \\
\hline $\mathrm{AL}$ & 24,5 & 107.682 & 43.073 & 8.814 & 21,4 & 9.218 & 18.032 & $104,6 \%$ \\
\hline$B A$ & 23,6 & 413.868 & 165.547 & 55.616 & 53,5 & 88.568 & 144.184 & $159,2 \%$ \\
\hline$M G$ & 33,7 & 306.080 & 122.432 & 28.776 & 14,8 & 18.120 & 46.896 & $63,0 \%$ \\
\hline RJ & 35,1 & 218.997 & 87.599 & 27.540 & 17,2 & 15.067 & 42.607 & $54,7 \%$ \\
\hline$S P$ & 40,3 & 430.317 & 172.127 & 117.744 & 42,7 & 73.498 & 191.242 & $62,4 \%$ \\
\hline PR & 36,2 & 133.931 & 53.572 & 71.953 & 55,2 & 29.572 & 101.525 & $41,1 \%$ \\
\hline SC & 38,7 & 67.728 & 27.091 & 12.932 & 11,0 & 2.980 & 15.912 & $23,0 \%$ \\
\hline RS & 39,3 & 70.560 & 28.224 & 2.447 & 2,5 & 706 & 3.554 & $28,8 \%$ \\
\hline MS & 37,3 & 40.055 & 16.022 & 7.066 & 22,2 & 3.557 & 10.623 & $50,3 \%$ \\
\hline MT & 40,7 & 38.588 & 15.435 & 14.526 & 34,7 & 5.356 & 19.882 & $36,9 \%$ \\
\hline GO & 31,5 & 163.535 & 65.414 & 17.591 & 28,7 & 18.774 & 36.365 & $106,7 \%$ \\
\hline
\end{tabular}

Fonte: Inep - Censo da Educação Superior - 2016. IBGE - Projeção da população. Sistematização e cálculo realizado por este estudo.

Analisando-se somente os desafios de expansão dos estados, por meio de suas UEs, tem-se evidenciado um cenário com consideráveis assimetrias, com nítidas desigualdades regionais, desigualdades entre os estados da federação e entre os estados de uma mesma região. Entre as regiões do país, tendo em vista 
a análise referente aos desafios de crescimento das UEs para colaborarem com o previsto na meta 12 , as regiões Norte e Nordeste são as que precisariam de maior ampliação de matrículas em suas UEs.

As UEs dos estados do Maranhão, Bahia, Pernambuco, Ceará e Alagoas precisariam de significativas taxas de crescimento em suas matrículas para contribuírem com o alcance de $50 \%$ de taxa bruta em seus estados e com o alcance da meta 12. No Maranhão, elas precisariam passar de 23.261 para 74.674 até 2024; na Bahia, de 55.616 para 144.184; em Pernambuco, de 17.115 para 40.579; no Ceará, de 41.101 para 96.447 e, em Alagoas, de 8.814 para 18.032.

Decorridos dois anos de vigência da meta 12 no que diz respeito à evolução das matrículas de graduação, isto é, de 2014 a 2016, os dados da tabela 6 apresentam a diferença das matrículas das UEs nesse intervalo, no Brasil. O resultado dessa análise apresenta a evolução do que já ocorreu nesses dois primeiros anos de vigência com relação à atuação dos estados, por meio de suas UEs, no que diz respeito ao proposto por essa meta ao país. No ano de 2016, havia 546.086 matrículas em UEs no Brasil. Então, considerando-se os dados de 2014, ocorreu um acréscimo de apenas 1.095 novas matrículas nas UEs nesse período.

Todavia, é preciso considerar que há diferença na análise das matrículas das UEs nesse período, quando elas são analisadas por estado, pois ocorreu a redução de matrículas em UEs nos estados do Amazonas, Roraima, Pará, Amapá, Tocantins, Maranhão, Rio Grande do Norte, Paraíba, Pernambuco, Alagoas, Bahia, Minas Gerais, Paraná, Santa Catarina e Goiás de acordo com os dados do Censo da Educação Superior do Inep.

Tabela 6 - Diferença das matrículas em UEs, entre os anos de 2016 e 2014. Acréscimo absoluto e percentual de crescimento de matrículas nas UEs para contribuírem com o êxito da meta 12 do PNE (2014-2024), segundo metodologia deste estudo, entre 2016 e 2024, no Brasil

\begin{tabular}{|c|c|c|c|c|c|c|c|}
\hline Estados & $\begin{array}{c}\text { Taxa } \\
\text { bruta } \\
2016\end{array}$ & $\begin{array}{c}\text { Total de } \\
\text { matrículas } \\
\text { das UEs } \\
\text { em 2014 }\end{array}$ & $\begin{array}{c}\text { Matrículas } \\
\text { nas UEs em } \\
2016\end{array}$ & $\begin{array}{c}\text { Diferença } \\
\text { entre as } \\
\text { matrículas } \\
\text { de 2016 e } \\
2014 \text { das } \\
\text { UEs }\end{array}$ & $\begin{array}{c}\text { Acréscimo } \\
\text { de } \\
\text { matrículas } \\
\text { necessário } \\
\text { nas UEs de } \\
2016 \text { a 2024 }\end{array}$ & $\begin{array}{c}\text { Crescimento } \\
\text { necessário } \\
\text { de 2016 a } \\
2024\end{array}$ & $\begin{array}{c}\text { Total de } \\
\text { matrículas } \\
\text { necessário nas } \\
\text { UES em 2024 } \\
\text { para contribuir } \\
\text { com a meta 12 } \\
\text { do PNE }\end{array}$ \\
\hline Brasil & 33,7 & 546.086 & 547.181 & 1.095 & 429.449 & $78,5 \%$ & 976.630 \\
\hline
\end{tabular}

Fonte: Inep - Censo da Educação Superior - 2014 e 2016. IBGE - Projeção da população. Sistematização e cálculo realizado por este estudo. 
Embora este estudo já tenha apresentado que o desafio proposto pelo conteúdo principal da meta 13 ao país já tenha sido superado, é preciso considerar as diferenças institucionais existentes em relação à titulação dos docentes que atuam na ES no Brasil, por categoria administrativa, em especial quanto às UEs. A partir dessa perspectiva, a tabela 7 apresenta os dados referentes ao percentual de mestres e doutores, e de doutores, das UEs por estados da federação no ano de 2016.

Tabela 7 - Total de funções docentes em exercício em UEs, percentual de mestres e doutores e somente doutores nos estados da federação que possuem UEs - 2016

\begin{tabular}{|c|c|c|c|}
\hline \multirow{2}{*}{$\begin{array}{l}\text { Estados que possuem } \\
\text { UEs }\end{array}$} & \multicolumn{3}{|c|}{2016} \\
\hline & Total & $\% M D$ & $\% D$ \\
\hline Amazonas & 1.045 & 76,6 & 29,2 \\
\hline Roraíma & 203 & 70,9 & 25,6 \\
\hline Pará & 1.196 & 77,0 & 30,7 \\
\hline Amapá & 169 & 62,7 & 12,4 \\
\hline Tocantins & 381 & 37,3 & 11,5 \\
\hline Maranhão & 1.893 & 52,2 & 19,5 \\
\hline Piauí & 1.087 & 65,3 & 27,0 \\
\hline Ceará & 2.261 & 75,6 & 38,3 \\
\hline Rio Grande do Norte & 917 & 67,1 & 28,6 \\
\hline Paraíba & 975 & 76,4 & 50,2 \\
\hline Pernambuco & 1.155 & 81,8 & 46,7 \\
\hline Alagoas & 548 & 70,1 & 18,8 \\
\hline Bahia & 4.429 & 83,7 & 46,1 \\
\hline Minas Gerais & 2.413 & 68,7 & 23,4 \\
\hline Rio de Janeiro & 3.007 & 95,9 & 83,4 \\
\hline São Paulo & 11.636 & 99,7 & 98,6 \\
\hline Paraná & 7.270 & 91,4 & 62,4 \\
\hline Santa Catarina & 1.195 & 92,1 & 55,8 \\
\hline Rio Grande do Sul & 257 & 97,7 & 62,6 \\
\hline Mato Grosso do Sul & 706 & 88,2 & 52,8 \\
\hline Mato Grosso & 1.262 & 79,8 & 36,6 \\
\hline Goiás & 1.845 & 54,9 & 22,1 \\
\hline
\end{tabular}

Fonte: - Inep - Censo da Educação Superior - 2012, 2014 e 2016. Sistematização e cálculo realizado por este estudo. 
Considerando o conteúdo principal da meta 13 e os dados da tabela 7 referente ao ano de 2016, havia UEs de 11 estados que ainda não possuíam, ou possuíam parcialmente, os percentuais previstos quanto à titulação de mestres e doutores, e de doutores, determinados por essa meta para o ano de 2024. Essas UEs são dos estados do Amazonas, Roraima, Pará, Amapá, Tocantins, Maranhão, Piauí, Rio Grande do Norte, Alagoas, Minas Gerais e Goiás. Essa é uma situação de alerta, pois nesses estados a titulação dos docentes de suas UEs está inferior à média nacional e ao proposto como parâmetro mínimo exigido pelo Plano ao país.

Este estudo também apurou qual seria o desafio de expansão de mestres e doutores titulados pelas UEs para que elas pudessem contribuir com o êxito da meta 14. Por essa direção, os dados das tabelas 8 apresentam o quantitativo total de mestres e doutores titulados no Brasil e em estados que possuem UEs, e o total de titulados em UEs no ano de 2014. No ano de 2014, do total dos mestres e doutores titulados no país, 12.029 e 5.555, ou seja, 23,3\% e 32,58\%, respectivamente, foram em UEs. A leitura desses dados por estado mostra a heterogeneidade das UEs do país, uma vez que fica evidente nos estados das regiões Centro-Oeste, Nordeste e Norte que a participação das UEs na oferta de pós-graduação stricto sensu ainda é incipiente, considerando o número de seus mestres e doutores titulados, em especial no que diz respeito aos doutores.

Tabela 8 - Total de mestres e doutores titulados nos estados da federação (que possuem UEs) e total em UEs - ano 2014

\begin{tabular}{|c|c|c|c|c|}
\hline $\begin{array}{c}\text { Estados que } \\
\text { possuem UEs }\end{array}$ & $\begin{array}{c}\text { Total de mestres } \\
\text { titulados em 2014 }\end{array}$ & $\begin{array}{c}\text { Total de doutores } \\
\text { titulados em 2014 }\end{array}$ & $\begin{array}{c}\text { Mestres titulados } \\
\text { em UEs em 2014 }\end{array}$ & $\begin{array}{c}\text { Doutores titulados } \\
\text { em UEs em 2014 }\end{array}$ \\
\hline Brasil & 51.527 & 17.048 & 12.029 & 5.555 \\
\hline AM & 471 & 77 & 74 & 4 \\
\hline RR & 97 & 0 & 16 & 0 \\
\hline PA & 1.109 & 223 & 90 & 0 \\
\hline AP & 36 & 5 & 0 & 0 \\
\hline TO & 143 & 0 & 0 & 0 \\
\hline MA & 378 & 30 & 55 & 0 \\
\hline PI & 387 & 31 & 13 & 0 \\
\hline $\mathrm{CE}$ & 1.433 & 403 & 333 & 28 \\
\hline $\mathrm{RN}$ & 1.124 & 356 & 98 & 0 \\
\hline $\mathrm{PB}$ & 1.413 & 362 & 185 & 2 \\
\hline $\mathrm{PE}$ & 1.963 & 687 & 162 & 1 \\
\hline $\mathrm{AL}$ & 334 & 36 & 0 & 0 \\
\hline
\end{tabular}


Tabela 8 - Total de mestres e doutores titulados nos estados da federação (que possuem UEs) e total em UEs - ano 2014

\begin{tabular}{|c|c|c|c|c|}
\hline $\begin{array}{c}\text { Estados que } \\
\text { possuem UEs }\end{array}$ & $\begin{array}{c}\text { Total de mestres } \\
\text { titulados em 2014 }\end{array}$ & $\begin{array}{c}\text { Total de doutores } \\
\text { titulados em 2014 }\end{array}$ & $\begin{array}{c}\text { Mestres titulados } \\
\text { em UEs em 2014 }\end{array}$ & $\begin{array}{c}\text { Doutores titulados } \\
\text { em UEs em 2014 }\end{array}$ \\
\hline BA & 1.950 & 450 & 654 & 54 \\
\hline MG & 5.453 & 1.653 & 157 & 8 \\
\hline RJ & 6.169 & 2.249 & 923 & 391 \\
\hline SP & 12.545 & 6.181 & 6.950 & 4.659 \\
\hline PR & 3.626 & 979 & 1.729 & 375 \\
\hline SC & 2.115 & 576 & 324 & 33 \\
\hline RS & 5.122 & 1.613 & 0 & 0 \\
\hline MS & 768 & 85 & 94 & 0 \\
\hline MT & 581 & 60 & 106 & 0 \\
\hline GO & 1.166 & 274 & 66 & 0 \\
\hline
\end{tabular}

Fonte: Geocapes - 2014. Sistematização realizada por este estudo.

A metodologia adotada por este estudo para a projeção e análise da contribuição das UEs na ampliação dos mestres e doutores a serem titulados para o cumprimento da meta 14 considera o percentual dos mestres e doutores titulados: 1) por todas as UEs do país do total dos titulados no Brasil, no ano de 2014; 2) por região e estado do total dos titulados no país, no ano de 2014; 3) em UEs, por região e estado, do total dos titulados em UEs, no Brasil. Isto é, o desafio de contribuição das UEs para com essa meta é apreciado por estado da federação tendo em vista esses critérios.

Por exemplo, o primeiro passo foi apurar o percentual dos mestres e doutores titulados pelas UEs em relação ao total dos mestres e doutores titulados no Brasil no ano de 2014. O segundo foi calcular o percentual de titulados por regiões e estados do total dos titulados do país. Como exemplo, no ano de 2014, dos 51.527 mestres titulados no Brasil, 768, que corresponde a 1,49\%, foram no estado do Mato Grosso do Sul. O terceiro passo foi calcular o percentual dos mestres titulados em UEs nas regiões e estados em relação ao total dos titulados das UEs no Brasil. Em 2014, dos 12.029 mestres titulados em UEs, no Brasil, 94, que corresponde a $0,78 \%$, foram titulados na Uems.

Por essa lógica de compreensão, tendo em vista os cálculos e critérios definidos e realizados por este estudo, considera-se que até 2024 haja 60.000 mestres titulados no Brasil, que as UEs continuem contribuindo com 23,5\% desse total dos mestres titulados no país, que o estado do Mato Grosso do Sul continue contribuindo com $1,49 \%$ do total dos mestres titulados no Brasil e que a UE 
desse estado continue contribuindo com $0,78 \%$ do total dos mestres titulados em UEs no Brasil. Essa mesma análise foi realizada para as projeções dos doutores titulados.

As informações das tabelas 9 mostram qual seria o total de mestres e doutores titulados no Brasil e nos estados que possuem UEs para o alcance da meta 14 e também qual seria a contribuição das UEs. Nessa direção, até o ano de 2024, as UEs do país precisariam titular um total de 14.007 mestres e 8.146 doutores, anualmente, para contribuírem para o êxito da meta. Desse total, 9.351 e 7.417, respectivamente, seriam em UEs da região Sudeste e 8.093 e 6.832, respectivamente, na USP, Unesp e Unicamp.

Tabela 9 - Total de mestres e doutores a serem titulados anualmente, nos estados da federação que possuem UEs, para o êxito da meta 14 PNE (2014-2024). Total de mestres e doutores a serem titulados por ano em UEs, até 2024, para elas contribuírem com o êxito dessa meta, conforme metodologia deste estudo

\begin{tabular}{|c|c|c|c|c|}
\hline $\begin{array}{l}\text { Estados que } \\
\text { possuem UEs }\end{array}$ & $\begin{array}{l}\text { Total de mestres a } \\
\text { serem titulados para } \\
\text { o êxito da meta }\end{array}$ & $\begin{array}{l}\text { Total de doutores a } \\
\text { serem titulados para } \\
\text { o êxito da meta }\end{array}$ & $\begin{array}{l}\text { Total de mestres a } \\
\text { serem titulados } \\
\text { em UEs para } \\
\text { contribuírem com o } \\
\text { êxito da meta }\end{array}$ & $\begin{array}{l}\text { Total de doutores } \\
\text { a serem titulados } \\
\text { em UEs para } \\
\text { contribuírem com o } \\
\text { exito da meta }\end{array}$ \\
\hline Brasil & 60.000 & 25.000 & 14.007 & 8.146 \\
\hline AM & 548 & 113 & 86 & 6 \\
\hline $\mathrm{RR}$ & 113 & 0 & 19 & 0 \\
\hline PA & 1.291 & 327 & 105 & 0 \\
\hline AP & 42 & 7 & 0 & 0 \\
\hline TO & 167 & 0 & 0 & 0 \\
\hline MA & 440 & 44 & 64 & 0 \\
\hline $\mathrm{PI}$ & 451 & 45 & 15 & 0 \\
\hline CE & 1.669 & 591 & 388 & 41 \\
\hline RN & 1.309 & 522 & 114 & 0 \\
\hline PB & 1.645 & 531 & 215 & 3 \\
\hline $\mathrm{PE}$ & 2.286 & 1.007 & 189 & 1 \\
\hline $\mathrm{AL}$ & 389 & 53 & 0 & 0 \\
\hline BA & 2.271 & 660 & 762 & 79 \\
\hline MG & 6.350 & 2.424 & 183 & 12 \\
\hline RJ & 7.183 & 3.298 & 1.075 & 573 \\
\hline SP & 14.608 & 9.064 & 8.093 & 6.832 \\
\hline PR & 4.222 & 1.436 & 2.013 & 550 \\
\hline SC & 2.463 & 845 & 377 & 48 \\
\hline
\end{tabular}


Tabela 9 - Total de mestres e doutores a serem titulados anualmente, nos estados da federação que possuem UEs, para o êxito da meta 14 PNE (2014-2024). Total de mestres e doutores a serem titulados por ano em UEs, até 2024, para elas contribuírem com o êxito dessa meta, conforme metodologia deste estudo

\begin{tabular}{|c|c|c|c|c|}
\hline $\begin{array}{c}\text { Estados que } \\
\text { possuem UEs }\end{array}$ & $\begin{array}{c}\text { Total de mestres a } \\
\text { serem titulados para } \\
\text { o êxito da meta }\end{array}$ & $\begin{array}{c}\text { Total de doutores a } \\
\text { serem titulados para } \\
\text { o êxito da meta }\end{array}$ & $\begin{array}{c}\text { Total de mestres a } \\
\text { serem titulados } \\
\text { em UEs para } \\
\text { contribuírem com o } \\
\text { êxito da meta }\end{array}$ & $\begin{array}{c}\text { Total de doutores } \\
\text { a serem titulados } \\
\text { em UEs para } \\
\text { contribuírem com o } \\
\text { êxito da meta }\end{array}$ \\
\hline RS & 5.964 & 2.365 & 0 & 0 \\
\hline MS & 894 & 125 & 109 & 0 \\
\hline MT & 677 & 88 & 123 & 0 \\
\hline GO & 1.358 & 402 & 77 & 0 \\
\hline
\end{tabular}

Fonte: Sistematização e cálculo realizado por este estudo.

Este estudo também analisou e calculou a diferença da evolução ocorrida no número de mestres e doutores titulados em UEs no Brasil, entre 2014 e 2016. Essa análise possibilitou apurar o quanto cada estado, por meio de suas UEs, já havia contribuído para o alcance da meta 14. Em 2016, foram 59.614 mestres e 20.603 doutores titulados no Brasil. Desse total, 13.855 e 6.664, respectivamente, foram titulados em UEs. Com essa evolução, mediante cálculos realizados por esta investigação, a contribuição das UEs nessa meta passou a ser de 880 novos mestres e de 1.639 novos doutores titulados, conforme apresentado pelos dados da tabela 10 .

Tabela 10 - Novas matrículas de pós-graduação stricto sensu necessárias para as UEs contribuírem com a meta 14 do PNE (2014-2024) até 2024, segundo metodologia deste estudo

\begin{tabular}{|c|c|c|c|c|c|c|c|}
\hline & $\begin{array}{c}\text { Acréscimo } \\
\text { de mestres } \\
\text { titulados } \\
\text { por ano } \\
\text { em UEs } \\
\text { entre 2016 } \\
\text { e 2024 } \\
\text { para 0 } \\
\text { exito da } \\
\text { meta 14 }\end{array}$ & $\begin{array}{c}\text { Acréscimo } \\
\text { de doutores } \\
\text { titulados } \\
\text { por ano em } \\
\text { UEs entre } \\
2016 \text { e 2024 } \\
\text { para o êxito } \\
\text { da meta 14 }\end{array}$ & $\begin{array}{c}\text { Relação entre } \\
\text { mestres } \\
\text { matriculados } \\
\text { e titulados } \\
\text { no Brasil em } \\
2016\end{array}$ & $\begin{array}{c}\text { Relação entre } \\
\text { doutores } \\
\text { matriculados } \\
\text { e titulados } \\
\text { no Brasil em } \\
2016\end{array}$ & $\begin{array}{c}\text { Acréscimo } \\
\text { de matrículas } \\
\text { em UEstrado } \\
\text { em Uessário } \\
\text { para } \\
\text { contribuir } \\
\text { com o êxito } \\
\text { da meta 14, } \\
\text { de 2016 a } \\
2024\end{array}$ & $\begin{array}{c}\text { Acréscimo } \\
\text { de matrículas } \\
\text { de doutorado } \\
\text { necessário } \\
\text { em UEs para } \\
\text { contribuir com } \\
\text { o êxito da meta } \\
14, \text { de 2016 a } \\
2024\end{array}$ & $\begin{array}{c}\text { Acréscimo } \\
\text { total de novas } \\
\text { matrí́culas na } \\
\text { pós-graduação } \\
\text { stricto sensu } \\
\text { em UEs para } \\
\text { contribuir com } \\
\text { ốxito da meta } \\
14, \text { de 2016 a } \\
2024\end{array}$ \\
\hline Brasil & 880 & 1.639 & 37,45 & 19,14 & 32.959 & 31.376 & 64.334 \\
\hline
\end{tabular}

Fonte. Sistematização e cálculos realizado por este estudo. 
Para que este estudo pudesse relacionar o quantitativo restante de mestres e doutores a serem titulados pelas UEs com o número necessário de novas matrículas, analisou-se a proporção existente entre o número de titulados e o número de matriculados no país, no ano de 2016. Nesse ano, havia, no Brasil, um total de 159.178 mestrandos e 107.640 doutorandos matriculados. O total de mestres titulados em relação ao total de mestres matriculados correspondia a $37,45 \%$ e o de doutores a $19,14 \%$. Nesse sentido, os dados da tabela 10 apresentam qual seria o total de novas matrículas que essas UEs precisariam ter em seus cursos de mestrado e doutorado para obterem o número necessário de novos titulados, isto é, seria necessário o acréscimo de 32.959 novas matrículas de mestrado e de 31.376 de doutorado nas UEs do país, para que elas contribuíssem com o êxito dessa meta.

Vale ressaltar que as UEs do país possuem perfis de atuação acadêmica muito distintos e muitas ainda possuem incipiente atuação na pós-graduação stricto sensu. Essa metodologia colabora para se pensar as projeções de expansão necessárias, tendo em vista o mesmo cenário percentual de titulados no ano de 2014.

\section{OS DESAFIOS DE FINANCIAMENTO DAS UEs, PERANTE AS METAS DE EXPANSÃO E QUALIDADE DA EDUCAÇÃO SUPERIOR DO PNE (2014-2024)}

Neste item, analisa-se qual seria o desafio de ampliação do financiamento das UEs para que elas contribuam com a expansão e o êxito das metas 12 e 14 . Os parâmetros utilizados para a análise dessa ampliação são a média do gasto por aluno dessas instituições, no período de 2012 a $2016^{1}$ e as projeções de ampliação das matrículas de graduação e pós-graduação stricto sensu das UEs que foram apresentadas nas tabelas 6 e 10. De acordo com os dados do Inep obtidos nos microdados do Censo da Educação Superior que foram tratados e sistematizados por este estudo, a média do volume total das despesas das 38 UEs, distribuídas em 22 estados, atingiram $R \$ 20.590 .241 .095,00$ gastos por ano no país com essas instituições, conforme apresentado nos dados da tabela 11.

1 Esse intervalo foi definido porque 2012 é o ano em que a lei do PNE considerou como ano inicial para o diagnóstico referente às metas da ES e o de 2016 por ser o dado mais recente disponível 
Tabela 11 - Total das despesas realizadas pelas UEs no Brasil e a média dessas despesas - 2012 a 2016 (Valores em R\$ a preços de janeiro de 2017 corrigidos pelo IPCA)

\begin{tabular}{|c|c|c|c|c|c|c|}
\hline Estado & $\mathbf{2 0 1 2}$ & $\mathbf{2 0 1 3}$ & $\mathbf{2 0 1 4}$ & $\mathbf{2 0 1 5}$ & $\mathbf{2 0 1 6}$ & Média \\
\hline Brasil & 20.591 .664 .741 & 21.403 .694 .570 & 20.761 .585 .618 & 20.116 .968 .258 & 20.077 .292 .288 & 20.590 .241 .095 \\
\hline
\end{tabular}

Fonte: Inep - Censo da Educação Superior (microdados) - 2012 a 2016. Sistematização e cálculo realizado por este estudo.

Despois de apurada a média do total das despesas das UEs no país, o passo seguinte foi apurar o gasto médio por aluno dessas instituições no Brasil. Esses valores referentes ao gasto médio das UEs no país entre 2012 e 2016, foram obtidos pela divisão do total das despesas apresentadas na tabela 11 pelo quantitativo total de alunos de graduação e de pós-graduação stricto sensu em UEs que constam dos dados do Inep e da Capes. A tabela 12 apresenta esses dados do gasto por aluno das UEs no Brasil, já sistematizados, entre 2012 e 2016, e também a média desse gasto nesse período que foi de $\mathrm{R} \$ 34.028,25$. É possível observar que a partir de 2013 o gasto médio por aluno dessas instituições está reduzindo.

\section{Tabela 11 - Total das despesas realizadas pelas UEs no Brasil e a média dessas despesas - 2012 a 2016 (Valores em R\$ a preços de janeiro de 2017 corrigidos pelo IPCA)}

\begin{tabular}{|c|c|c|c|c|c|c|}
\hline Estado & $\mathbf{2 0 1 2}$ & $\mathbf{2 0 1 3}$ & $\mathbf{2 0 1 4}$ & $\mathbf{2 0 1 5}$ & $\mathbf{2 0 1 6}$ & Média \\
\hline Brasil & $33.819,70$ & $36.539,98$ & $34.144,93$ & $32.971,83$ & $32.664,81$ & $34.028,25$ \\
\hline
\end{tabular}

Fonte: Inep - Censo da Educação Superior e Geocapes - 2012 a 2016. Sistematização e cálculo realizado por este estudo.

Tendo em vista o acréscimo anual total de 544.227 novas matrículas necessárias nas UEs no Brasil e a média do gasto aluno dessas instituições no país, a projeção do total dos recursos para a promoção dessa expansão seria de R $\$$ 18.519.091.261,98, ou seja, seria preciso quase dobrar o volume de recursos, uma vez que a média do total das despesas dessas instituições, no Brasil, entre 2012 e 2016, foi de $\mathrm{R} \$ 20.591 .664 .741,00$. 
Tabela 13 - Projeção da expansão de recursos necessários, de 2016 a 2024, para que as UEs, por estado da federação, contribuam com a expansão prevista nas metas do PNE (2014-2024) para a ES, segundo a metodologia deste estudo

(Valores em $\mathbf{R} \$$ a preços de janeiro de 2017 corrigidos pelo IPCA)

\begin{tabular}{|c|c|c|c|}
\hline Estado & $\begin{array}{c}\text { Média do gasto aluno } \\
\text { das UEs }\end{array}$ & $\begin{array}{c}\text { Acréscimo necessário de } \\
\text { matrículas de graduação e } \\
\text { pós-graduação stricto sensu } \\
\text { nas UEs, de 2016 a 2024 }\end{array}$ & $\begin{array}{c}\text { Acréscimo de recursos necessário } \\
\text { para contribuir com a expansão das } \\
\text { metas do PNE (2014-2024) para a ES, } \\
\text { segundo metodologia deste estudo }\end{array}$ \\
\hline Brasil & $34.028,25$ & 544.227 & $18.519 .091 .261,98$ \\
\hline
\end{tabular}

Fonte: Sistematização e cálculo realizado por este estudo.

A análise dos gastos com a educação e sua comparação com o percentual do Produto Interno Bruto (PIB) compõem uma tarefa necessária a ser assumida pelos estudiosos da área do seu financiamento, em especial após a aprovação desse Plano que estabeleceu, na meta 20, essa vinculação. Nesse sentido, os dados da tabela 14 mostram os valores do PIB do Brasil entre 2012 a 2015 que, juntamente com os dados constantes das tabelas 11 e 12, foram utilizados para apurar o total das despesas das UEs do Brasil, como percentual do PIB nacional.

Tabela 14 - Produto Interno Bruto (PIB) do Brasil - 2012 a 2015

(Valores em R\$ a preços de janeiro de 2017 corrigidos pelo IPCA)

\begin{tabular}{|c|c|c|c|}
\hline $\mathbf{2 0 1 2}$ & $\mathbf{2 0 1 3}$ & $\mathbf{2 0 1 4}$ & $\mathbf{2 0 1 5}$ \\
\hline 6.593 .399 .220 .619 & 6.874 .667 .530 .480 & 7.007 .930 .345 .546 & 6.668 .702 .743 .126 \\
\hline
\end{tabular}

Fonte: IBGE - Contas regionais - 2012 a 2015.

No ano de 2012, as despesas das UEs representaram 0,31\% do PIB do país; em 2013, esse percentual foi de 0,31\%; em 2014, de 0,30\%; e, em 2015, de $0,30 \%$. Sendo assim, a média desse período foi $0,31 \%$, conforme dados da tabela 15.

Tabela 15 - Evolução do total das despesas realizadas pelas UEs do Brasil, como percentual do PIB nacional, e a média do período - 2012 a 2015

\begin{tabular}{|c|c|c|c|c|}
\hline $\mathbf{2 0 1 2}$ & $\mathbf{2 0 1 3}$ & $\mathbf{2 0 1 4}$ & $\mathbf{2 0 1 5}$ & Média \\
\hline 0,31 & 0,31 & 0,30 & 0,30 & 0,31 \\
\hline
\end{tabular}

Fonte: Sistematização e cálculos realizados por este estudo. 
Por fim, a tabela 16 contém os dados referentes ao volume total de recursos necessários para que as UEs do país contribuíssem com a expansão proposta pelas metas para a ES e os valores dessa ampliação como percentual do PIB nacional. O acréscimo total de recursos necessários no valor $\mathrm{R} \$ 18.519 .091 .262$ corresponde a 0,28\% do PIB nacional de 2015 e os $\mathrm{R} \$ 39.109 .332 .357,00$, que corresponde ao total de recursos necessários para a promoção da expansão das UEs, corresponderia a $0,59 \%$. Esse crescimento nos recursos seria equivalente a $89,9 \%$, ou seja, para a superação do desafio de expansão das UEs, proposta por este estudo, seria preciso quase dobrar o volume total dos recursos destinados a essas instituições.

Tabela 16 - Acréscimo de recursos das UEs no Brasil como percentual do PIB nacional de 2015. Estimativa do total do PIB nacional a ser gasto com as UEs para contribuir com as metas do PNE (2014-2024) para a ES. Percentual de crescimento dos recursos necessários para a expansão (Valores em $\mathbf{R} \$$ a preços de janeiro de 2017 corrigidos pelo IPCA)

\begin{tabular}{|c|c|c|c|c|c|}
\hline $\begin{array}{l}\text { Média do total } \\
\text { das despesas } \\
\text { das UEs, entre } \\
2012 \text { e } 2016\end{array}$ & $\begin{array}{c}\text { Total de } \\
\text { recursos } \\
\text { necessários } \\
\text { para a } \\
\text { expansão* }\end{array}$ & $\begin{array}{l}\text { Média dos } \\
\text { gastos de } \\
\text { todas as UEs } \\
\text { do país como } \\
\text { percentual } \\
\text { nacional, entre } \\
2012 \text { e } 2015\end{array}$ & $\begin{array}{c}\text { Acréscimo de } \\
\text { novos recursos } \\
\text { necessários, } \\
\text { como } \\
\text { percentual do } \\
\text { PIB nacional } \\
\text { de } 2015, \\
\text { para as UÉs } \\
\text { contribuírem } \\
\text { com as metas } \\
\text { até } 2024\end{array}$ & $\begin{array}{l}\text { Estimativa do } \\
\text { total do PIB } \\
\text { nacional a } \\
\text { ser gasto com } \\
\text { todas as UEs } \\
\text { do país para } \\
\text { contribuírem } \\
\text { com as metas } \\
\text { até } 2024\end{array}$ & $\begin{array}{c}\% \text { de } \\
\text { crescimento } \\
\text { dos recursos } \\
\text { necessários } \\
\text { para a } \\
\text { expansão até } \\
2024\end{array}$ \\
\hline 20.590 .241 .095 & 39.109 .332 .357 & 0,31 & 0,28 & $0,59 \%$ & $89,9 \%$ \\
\hline
\end{tabular}

Dados das tabelas 55, 57 e 67 . Sistematização e cálculo realizado por este estudo.

* Valor obtido pela soma da média do total das despesas das UEs, entre 2012 e 2016 contido na tabela 11, mais o acréscimo de recursos necessários para contribuir com a expansão das metas do PNE para a ES, contido na coluna 4 da tabela 13.

Esse cenário de imperativos desafios que seria imposto aos estados da federação para promoverem a expansão de suas UEs é muito audacioso. Nessa perspectiva, é relevante destacar o teor do conteúdo da estratégia 12.18 do PNE (2014-2024), para que os estados, por meio de suas UEs, possam contribuir com o êxito dessas metas. Essa estratégia tem por objetivo estimular a expansão das IES estaduais e municipais, por meio de colaboração técnica e financeira do governo federal. A efetividade da estratégia 12.18 do PNE (2014-2024) torna-se essencial para que os estados possam colaborar com o êxito das metas do Plano para a ES. 


\section{CONSIDERAÇÕES FINAIS}

A investigação sobre os desafios e projeções para o alcance das metas 12, 13 e 14 no Brasil, mostrou que a meta 12 possui o conteúdo mais desafiador a ser alcançado no país. As projeções realizadas por esta pesquisa apontaram que seria necessário um crescimento de 49\% nas matrículas de graduação do país de 2014 a 2024 e de $79 \%$ nas matrículas públicas para o êxito de $50 \%$ de taxa bruta, no ano de 2024, com 40\% da nova expansão em matrículas públicas.

O desafio de expansão das matrículas públicas para o alcance da meta 12 e o percentual de oferta de matrículas públicas das UEs, no ano de 2014, foram os principais parâmetros utilizados por este estudo para calcular qual seria a contribuição das UEs para o êxito dessa meta. Nessa direção, seria necessário que as UEs do país criassem 430.544 novas matrículas de 2014 a 2024, para que elas contribuíssem para o proposto por essa meta. Sendo assim, essas novas matrículas representariam $78,8 \%$ de crescimento, uma audaciosa expansão, tendo em vista o contexto de redução dessa oferta pelas UEs no país.

A análise realizada indicou que a ampliação do financiamento dos estados, por meio de suas UEs para contribuírem com o alcance das metas do PNE para a ES, mostrou-se bastante audaciosa; seria necessário um crescimento de $89,9 \%$ no volume total dos recursos dessas instituições para que elas contribuam com o êxito das metas para a ES, isto é, um acréscimo de $\mathrm{R} \$$ 18.519.091.262,00. Assim, conclui-se que o volume anual total de recursos necessários para que as UEs colaborem com a expansão das metas para a ES deveria ser de $\mathrm{R} \$ 39.109 .332 .357,00$, correspondendo a 0,59\% do PIB nacional. Isto é, seria necessário quase dobrar o volume dos recursos destinados às UEs do país, ou seja, uma ampliação de recursos muito desafiadora aos estados que já possuem outros imperativos desafios determinados pelo PNE a serem superados em relação à Educação Básica.

Tendo em vista os dados e análises apresentados por este estudo, concluise que a efetivação da estratégia 12.18 do PNE, que prevê destinação de recursos federais para a promoção da expansão das UEs para que elas possam contribuir para o alcance das metas para a ES, é fundamental para a expansão das UEs. Isso porque seria impeditivo para a maioria dos estados que ofertam ES pública assumirem a duplicação dos recursos para a promoção da expansão necessárias nas UEs.

É preciso ressaltar as mudanças ocorridas no cenário político-econômico do país a partir de 2016, especialmente após o processo de impeachment da presidente, democraticamente eleita, Dilma Roussef, substituída pelo vice-presidente Michel Temer, do Partido do Movimento Democrático Brasileiro (PMDB). A agenda 
adotada por esse novo governo pode ser caracterizada como regressiva, no que diz respeito aos aspectos sociais, porque possui forte ênfase no alinhamento de suas ações com as políticas neoliberais, visando a atender aos interesses do sistema financeiro e dos grupos empresariais nacionais e internacionais, por meio de reformas estruturais na legislação trabalhista, educacional e financeira do país.

Entre as mudanças implementadas pelo governo do presidente Michel Temer, é preciso destacar que a aprovação da EC n. ${ }^{\circ}$ 95/2016, que instituiu uma nova política de regime fiscal para a União, certamente comprometerá o alcance do que está estabelecido pelas metas do Plano. Há estudos que apontam que a "EC/95 determinou a 'morte' do PNE" (AMARAL, 2017, p. 24), uma vez que o cumprimento de suas metas, nesse contexto de ajuste fiscal, "é praticamente impossível” (Ibidem, 2017, p. 24). As tendências que se apresentam sobre a não centralidade conferida ao PNE (2014-2024) como política de Estado para a educação são muito preocupantes, visto que a EC 95/2016 pode ser considerada uma revogação indireta das metas e estratégias contidas no Plano, em especial quanto à ampliação de recursos que está prevista no conteúdo da meta 20.

Além das mudanças ocorridas no contexto político-econômico na esfera federal, é preciso considerar seus desdobramentos no âmbito de vários estados brasileiros, que enfrentam processos de crises e de ajustes fiscais que já atingiram várias UEs do país e podem comprometer, sobremaneira, a ação dos estados para com as metas do Plano, especialmente quanto à contribuição das UEs no alcance das metas para a ES.

De forma geral, é possível concluir que o alcance das metas do PNE (2014-2024) para a ES, e a consequente contribuição das UEs, mostra-se muito desafiadora e requer: a revogação da EC n. ${ }^{\circ}$ 95/2016 para a ampliação dos recursos públicos (federais e estaduais) atualmente destinados a essas instituições; alteração do atual cenário de redução na expansão de matrículas, e matrículas públicas, que ocorreu nos dois primeiros anos de vigência do Plano e a retomada do seu crescimento; a efetivação da estratégia 12.18 .

\section{REFERÊNCIAS}

AMARAL, Nelson Cardoso. Com a PEC 241/55 (EC 95) haverá prioridade para cumprir as metas do PNE (2014- 2024)? Revista Brasileira de Educação (RBE), vol. 22, núm. 71, 2017, pp. 1-25 Associação Nacional de Pós-Graduação e Pesquisa em Educação Rio de Janeiro, Brasil, 2017. 
BRASIL. Instituto Nacional de Estudos e Pesquisas Educacionais Anísio Teixeira (Inep). Sinopse Estatística do Censo da Educação Superior. Brasília, DF: MEC, 2014 a 2016.

Lei n. ${ }^{\circ}$ 13.005, de 25 de junho de 2014. Aprova o Plano Nacional de Educação - PNE e dá outras providências. Diário Oficial da União, Brasília, DF, 2014.

Instituto Brasileiro de Geografia e Estatística (IBGE). Projeções da população brasileira por sexo e idade para o período de 2000 a 2060. Brasília, DF, 2013.

Lei n. ${ }^{\circ}$ 9.394, de 26 de dezembro de 1996. Estabelece as Diretrizes e Bases da Educação Nacional, Brasília, DF, 1996.

CARVALHO, Renata Ramos da Silva. Universidade Estadual de Goiás: histórico, realidade e desafios. 2013. 202 f. Dissertação (Mestrado em Educação) - Universidade Federal de Goiás, Goiânia, 2013.

DOURADO, Luiz Fernandes (Org.). Plano Nacional de Educação - PNE (2014-2024): avaliação e perspectivas. Campinas: Mercado das Letras, 2017.

Plano Nacional de Educação: o epicentro das políticas de Estado para a educação brasileira. Goiânia: Editora da Imprensa Universitária e ANPAE, $2017 b$.

FIALHO, Nadia Hage. Nadia Hage. Universidade Multicampi. Brasília, DF: Autores Associados; Plano Editora, 2005.

MARTINS, Carlos Benedito. O ensino superior brasileiro nos anos 90. Perspectiva. v.14, n.1, p. 41-60, São Paulo, jan./mar. 2000.

SAMPAIO, Helena; BALBACHEVSKY, Elizabeth; PEÑALOZA, Verónica. Universidades estaduais no Brasil: características institucionais. São Paulo: NUPES/USP, 1998. (Documento de Trabalho n. ${ }^{\circ} 4$ ) 
RENATA RAMOS DA SILVA CARVALHO possui graduação em História pela Universidade Estadual de Goiás (UEG). Mestre e Doutora em Educação pela Universidade Federal de Goiás (UFG). Professora efetiva da UEG Campus Inhumas. Pesquisadora na área de Políticas Educacionais, gestão e financiamento com ênfase em educação superior e universidades estaduais. E-mail: renataramosprof@yahoo.com.br

NELSON CARDOSO AMARAL possui Mestrado em Física pela Universidade Católica do Rio de Janeiro e Doutorado em Educação pela Universidade Metodista de Piracicaba (Unimep). É professor Associado II, aposentado, da Universidade Federal de Goiás. Pesquisador na área de políticas educacionais com ênfase financiamento, gestão e avaliação educacional. E-mail: nelsoncardosoamaral@ gmail.com 